\title{
PROCESOS INNOVADORES, PERCEPCIÓNY NUEVOS PERFILES EN VENTA DE TECNOLOGÍAS Y DISEÑO DE GESTIÓN DE CATEGORÍAS
}

\author{
CASO DE ESTABLECIMIENTOS DE RETAIL
}

\author{
Richard Orlando Buitrago Reyes* Jaime Andrés Reyes Páez **
}

\section{RESUMEN}

Se realizó una investigación comparativa acerca de la percepción, consumo y perfiles de los usuarios en procesos de uso y venta de software, hardware, dispositivos y suministros complementarios relacionados con la informática. Se hizo en negocios de ventas al detal, centros comerciales, supermercados, el Centro de Alta Tecnología y Unilago, es decir, tiendas especializadas en la oferta al detal de productos con alta tecnología. Tiendas de mercado nacional e internacional de Bogotá D.C. En el diseño metodológico se evidenciaron estrategias de comunicación, mensajes requeridos, modelos de activación de la marca, dinámicas de respuesta a los informes y presentaciones, posicionamiento y mercado objetivo, comportamientos y análisis de las estadísticas de ventas, diferenciales competitivos y mejores ubicaciones. El estudio detallado buscó diagnosticar la historia de venta al detal, las tendencias de consumo y las variables correspondientes. Igualmente, se contextualizó con referencias internacionales, textos especializados, cuestionarios, instrumentos y documentos de resultados, expuestos por universidades de Bogotá, por Fenalco, Fedesarrollo, la Cámara de Comercio y Acopi.

\section{PALABRAS CLAVE}

Gadget, gestión de categorías, hardware, percepción, perfiles, retail, software, suministros.

\begin{abstract}
We performs a comparative research on perception, consumption and user profiles processes and sale of software, hardware, devices and related supplies complementary information. It was made in retail businesses, shopping malls, supermarkets, the Center for High Technology and Unilago, we said, the shops offer
\end{abstract}

\footnotetext{
* Doctor in Business Administration Major in Marketing, Atlantic International University. Maestría en Administración y Especialista en Gerencia de Gestión y Currículo, Universidad Externado de Colombia. Administrador de Empresas, Universidad de La Salle. Docente, Escuela Colombiana de Carreras Industriales. Miembro del Grupo de Investigación en Ciencias Económicas y Administrativas _GICEA. rbuitragor@ecci.edu.co, grupo.gicea@ ecci.edu.co.

** Maestría en mercadeo, Universidad de New South Wales, Australia. Esp. New Media Management, Birbeck College, Universidad de Londres. Publicista, Universidad Jorge Tadeo Lozano. Miembro del Grupo de Investigación en Ciencias Económicas y Administrativas —GICEA. jreyesp@ecci. edu.co, jameta8o@gmail.com, grupo.gicea@ecci.edu.co.
} 
retail products with high technology. Stores national and international market Bogotá DC In the methodological design communication strategies required messages, activation models of the brand, dynamic response to reports and presentations, positioning and target behaviors and analyzing sales statistics, competitive advantages and market best locations were evident. The detailed study sought to diagnose the history of retail, consumer trends and related variables. It was also contextualized with international references, specialized texts, questionnaires, instruments and documents results presented by universities in Bogota, by Fenalco Fedesarrollo, the Chamber of Commerce and Acopi.

\section{KEYWORDS}

Retail, Category Management, perception, Profiles, Hardware, Software, Gadget and Supplies.

\section{TABLA DE ACRÓNIMOSY SIGLAS}

Fenalco: Federación Nacional de Comerciantes

Acopi: Asociación Colombiana de Pymes

CAT: Centro de Alta Tecnología (Bogotá DC)

Fedesarrollo: Fundación para la Educación Superior y el Desarrollo (Centro de investigación económica y social).

Cámara de Comercio: Cámara de Comercio de Bogotá (Entidad privada sin ánimo de lucro que promueve el crecimiento económico y el desarrollo de la competitividad).

\section{INTRODUCCIÓN}

1.1 Clasificación en la lista del Global Powers of Retailing: En su tercera edición de Perspectivas de la Economía Mundial (2013), Deloitte Touche Tohmatsu Limited se muestra como una de las cuatro grandes empresas que miden la inversión y la participación de la venta al por menor (retail) en la gestión de lineales, la auditoría y en sistema de servicios de riesgo empresarial en el mundo. Publican un documento de medición anual de las 250 empresas más representativas de penetración de retail en el mundo. Sus estadísticas muestran que Latinoamérica presenta un crecimiento ponderado en la participación de este tipo de mercado: mientras en Estados Unidos la tendencia se estabilizó hacia el año 2011, en América Latina aumentó en un 1,3\%, pese al comportamiento negativo del retail en el mundo, como ocurrió entre 2010 y 2011, cuando cayó al - 6,1 \%. Se presentan casos de éxito, como el de la transnacional brasileña Pão de Açúcar, que desplazó del primer lugar del índice latinoamericano a Cencosud y ascendió 17 puestos en la lista mundial de Global Powers of Retailing, la "Global P of R". En la tabla 1 se puede observar las principales participaciones de mercados al detal en el mundo. 
Tabla 1. Principales hipermercados de ventas al por menor

\begin{tabular}{|c|c|c|c|c|c|c|c|c|}
\hline Tabla & \multicolumn{8}{|c|}{ Top 250 (US\$mil) } \\
\hline $\begin{array}{c}\text { Growth } \\
\text { opera- } \\
\text { tions }\end{array}$ & $\begin{array}{l}\text { Name of } \\
\text { company }\end{array}$ & $\begin{array}{c}\text { Country } \\
\text { of }\end{array}$ & $\begin{array}{l}\text { Retail } \\
\text { revenue }\end{array}$ & $\begin{array}{l}\text { Retail } \\
\text { revenue }\end{array}$ & $\begin{array}{l}\text { Net profit } \\
\text { margin }\end{array}$ & $\begin{array}{l}\text { Return } \\
\text { on as- } \\
\text { sets }\end{array}$ & $\begin{array}{l}\text { \# coun- } \\
\text { tries of } \\
\text { operation }\end{array}$ & $\begin{array}{l}\text { \% retail } \\
\text { revenue } \\
\text { from } \\
\text { foreign }\end{array}$ \\
\hline 1 & Wal-Mart & U.S.A & $\$ \quad 446.950$ & $6,00 \%$ & $3,70 \%$ & $8,50 \%$ & 28 & $28,40 \%$ \\
\hline 2 & Carrefour & France & \$ $\quad 113.197$ & $-9,80 \%$ & $0,50 \%$ & $0,80 \%$ & 33 & $56,70 \%$ \\
\hline 3 & Tesco U.K. & U.K & \$ 101.574 & $5,80 \%$ & $4,40 \%$ & $5,50 \%$ & 13 & $34,50 \%$ \\
\hline 4 & Metro & Germany & $\$ \quad 92.905$ & $-0,80 \%$ & $1,10 \%$ & $2,20 \%$ & 33 & $61,10 \%$ \\
\hline 5 & Kroger U.S. & U.S.A & $\$ 90.374$ & $10,00 \%$ & $0,70 \%$ & $2,50 \%$ & 1 & $0,00 \%$ \\
\hline 6 & Costco U.S & U.S.A & $\$ \quad 88.915$ & $14,10 \%$ & $1,70 \%$ & $5,80 \%$ & 9 & $27,00 \%$ \\
\hline 7 & Schwarz & Germany & $\$ \quad 87.841$ & $5,80 \%$ & & & 26 & $55,80 \%$ \\
\hline 8 & Aldi & Germany & $\$ \quad 73.375$ & $3,70 \%$ & & & 17 & $57,10 \%$ \\
\hline 9 & Walgreen & U.S.A & $\$ \quad 72.184$ & $7,10 \%$ & $3,80 \%$ & $9,90 \%$ & 2 & $1,50 \%$ \\
\hline 10 & $\begin{array}{c}\text { The Home } \\
\text { Depot } \\
\text { U.S.A }\end{array}$ & & $\$ \quad 70.395$ & $3,50 \%$ & $5,50 \%$ & $9,60 \%$ & 5 & $11,40 \%$ \\
\hline Top 10* & & & $\$ 1.237 .710$ & $4,40 \%$ & $2,90 \%$ & $6,20 \%$ & 16,7 & $32,90 \%$ \\
\hline Top 250* & & & $\$ 4.271 .171$ & $5,10 \%$ & $3,80 \%$ & $5,90 \%$ & 9 & $23,80 \%$ \\
\hline
\end{tabular}

Fuente: Global Powers of Retailing 2011 tomado de Retail Beyond, Retail perspectives from Deloitte 2013.

La crisis económica ha afectado a nivel mundial el mercado del retail, pero en América Latina ha crecido, según el informe 2014 del Global Powers of Retailing. Esta es, tal vez, una tendencia de expansión en los países con mercados emergentes, incluidos los de Suramérica como Brasil, Argentina, Chile, Perú y Colombia. Su crecimiento ha sido constante en los últimos tres años, pues de los 250 de los mayores de la lista, 147 operan en más de un país y, de estos, 115 están ubicados en más de una subregión como Sudamérica según la Comisión Económica para América Latina y el Caribe (Cepal). La tabla 2, muestra el número de las principales compañías por continentes, inclusive América Latina. 
Tabla 2. Número de compañías de venta al por menor en el ámbito Mundial. Participación por continentes

\begin{tabular}{|c|c|c|c|c|c|c|}
\hline Tabla No 2 & \multicolumn{6}{|c|}{$\begin{array}{l}\text { Top } 250 \text { Región Country Profiles \# companie Average retail } \\
\text { revenue (US } \$ \text { mil) \% retail revenue from foreign operations }\end{array}$} \\
\hline Región Country & $\begin{array}{l}\text { Profiles \# } \\
\text { companie }\end{array}$ & & $\begin{array}{l}\text { lerage } \\
\text { revenue } \\
\text { S\$mil) }\end{array}$ & $\%$ single- & $\begin{array}{l}\% \text { retail } \\
\text { revenue }\end{array}$ & $\begin{array}{l}\text { from foreign } \\
\text { operations }\end{array}$ \\
\hline Africa/Middle East & 7 & $\Phi$ & 6.474 & $26,90 \%$ & 1,03 & $0,00 \%$ \\
\hline Asia/Pacific & 58 & $\$$ & 11.009 & $11,60 \%$ & 5 & $51,70 \%$ \\
\hline Japan & 40 & $\$$ & 9.608 & $6,60 \%$ & 3,4 & $62,00 \%$ \\
\hline Other Asia/Pacific & 18 & $\$$ & 14.124 & $19,20 \%$ & 8,5 & $33,30 \%$ \\
\hline Europe & 88 & $\$$ & 18.685 & $38,20 \%$ & 15 & $19,30 \%$ \\
\hline France & 13 & $\$$ & 30.555 & $43,20 \%$ & 30 & $0,00 \%$ \\
\hline Germany & 18 & $\$$ & 24.977 & $42,90 \%$ & 14,6 & $11,10 \%$ \\
\hline U.K. & 15 & $\Phi$ & 18.320 & $23,00 \%$ & 17,1 & $20,00 \%$ \\
\hline Latin America & 11 & $\Phi$ & 8.518 & $17,80 \%$ & 2 & $54,50 \%$ \\
\hline North America* & 86 & $\$$ & 21.504 & $15,30 \%$ & 6,2 & $48,80 \%$ \\
\hline U.S.* & 76 & $\$$ & 22.713 & $15,30 \%$ & 6,8 & $44,70 \%$ \\
\hline
\end{tabular}

Results reflect Top 250 retailers headquartered in each region/country, * Average number of countries excludes Dell (U.S.), whose near-global coverage would skew the average

Fuente: Global Powers of Retailing (2011, g. 18).

La participación de América Latina, en cuanto a la inversión extranjera, es del 17,8\%, por encima de Asia, con el 11,6\%, y de Japón con el 6,6\%. Con respecto a la participación total, frente a la mundial, es del $5,2 \%$, con un crecimiento del $1,3 \%$, pequeña aún si se compara con Estados Unidos (33,6\%), Europa (18\%) o Japón (12,8\%).
El anterior diagnóstico se hizo para contextualizar la investigación y darle respuesta a los interrogantes de quienes se están dedicando a la venta de productos de alta tecnología bajo sus espacios de retail. Para tal efecto, el grupo GICEA se propuso conocer a fondo todo el tema de la venta al por menor en el mundo, examinar luego su desarrollo en América La- 
tina y, por último, observar con detenimiento cómo ha sido la incursión y los modelos de inversión de las grandes cadenas transnacionales en el mercado de Bogotá, así como su competitividad frente al CAT y Unilago. Se formaron grupos de investigación en la Facultad de Ciencias Económicas y Administrativas de la ECCI. Mientras la Línea "Gestión Organizacional Productividad e Innovación" (GOPI) acogió la temática a través del programa de Mercadeo y Publicidad, las sublíneas Comunicación integrada de marketing, consumo, gestión de categorías, retail y logística abordaron el tema a lo largo del contexto.

Los conceptos Retail y Small Retail son comunes a nivel mundial, pero nuevos para Colombia. Así lo explican Meyer (2009) y la lista de Changing de Mix (2013, p. 11) de Deloitte, quienes definen el término retail, proveniente del inglés, como comercio al detal o al por menor. El retail engloba un sector de negocios que tienen que ver con tiendas que venden alta tecnología, gadget, accesorios y el diseño. Tal sector incluye supermercados, tiendas de marca pequeñas, medianas y grandes superficies de venta al menudeo, centros comerciales, así como el comercio de la banca y los alimentos. En el Global P of R, el retail está relacionado con cadenas de tiendas, franquicias, centrales de compras, venta de espacios y ventas en línea o "e-retail". Es decir, son espacios de intercambio de productos por medio de los cuales se realiza gestión por categoría y se establecen nuevos modelos estratégicos de inversión para góndolas, lineales y espacios de exhibición.

1.2 Comportamiento, perfiles y percepción de los consumidores con respecto a centros de venta de tecnología y grandes superficies: Al abordar el tema de comportamiento, venta, perfiles, percepción y uso de nuevas tecnologías, se debe tener en cuenta lo explorado por el Ministerio de Educación Nacional acerca de la infraestructura tecnológica en el país. Esta ha venido en progreso desde el año 2005, a partir del levantamiento y mejoras de infraestructura tecnológica. En ese sentido, también los establecimientos educativos han venido creciendo, es decir, su estado actual y su desarrollo se pueden medir por el número de consumidores habituales, generalmente estudiantes, profesionales y egresados de las universidades que desean actualizarse constantemente en los diferentes usos de dispositivos que tienen como propósito una función específica pero que varían de forma y proporción, con tamaños pequeños, denominados "gadget".

En cuanto al uso y acogida de nuevas tecnologías, se observa que, para la Connectivity Scorecard, el desarrollo de las tecnologías de la información y la comunicación (TIC) se constituye en una herramienta que impulsa la economía nacional, ya que permite mejorar el ejercicio económico y la productividad a través del uso de estas. Las TIC hacen parte de la cultura tecnológica y configuran la sociedad de la información, presente en el diario vivir; asimismo, un buen manejo y provecho de estas tecnologías permite la ampliación de capacidades físicas y mentales con el fin de obtener un progreso en el desarrollo social.

Según la información obtenida, se han adelantado proyectos como la conectividad en banda ancha en establecimientos públicos (Instituciones Educativas Oficiales) en sus fases I y II. Actualmente, se desarrolla la fase III. Con base en la información que se recopila a través de dicho sistema, se podrán desarrollar fases futuras en proyecto de conectividad, así como las aplicaciones y usos de últimas y renovadas tecnologías.

MET\&FLU No o8 "Metrología de Fluidos" es la revista que está directamente relacionada con la disponibilidad y la calidad de la infraestructura utilizable en el país. Precisamente a raíz de su investigación sobre el desarrollo tecnológico y la educación en el país, de acuerdo con la capacidad de gasto, esta publicación plantea que Colombia seguirá creciendo gracias al fortalecimiento de dichos sectores por parte del Ministerio de Tecnologías de la Información y las 
Comunicaciones, lo que conllevará a un crecimiento ponderado en las tendencias de compra de los elementos correspondientes.

Según de Technology Advances in Retail Improving Margins using Wireless Networks, en los centros de alta tecnología como el CAT deben estudiarse con vehemencia los aciertos y desaciertos en el ejercicio mercantil, las ventas al detal, la ignorancia de una política clara de precios y el establecimiento de precios finales con un uso estratégico de canales de distribución, producto y promoción acertados. A lo largo de la investigación, se observaron problemas que involucraron percepción, perfiles, estilos de compra y deficiencias en la ejecución de estrategias en los centros objeto de estudio. Una de la tareas imprescindibles fue identificar las variables de marketing con las cuales se examinarían los Centros de Alta Tecnología que ofrecen este tipo de tecnologías, teniendo en cuenta lo propuesto por Honghua Tan (2013) con respecto a la venta de este tipo de artículos que se han disparado a nivel mundial y especialmente en América Latina.

Con el fin de indagar sobre los temas de percepción, perfiles y valores de uso en el consumo, se hace necesario utilizar una medida dada desde la teoría: los profesores Brett King y Wertheimer (2009) hablan de la dinámica de la logística y la percepción en los procesos tecnológicos. En sus aportes de Gestalt Theory describen cómo ha sido la evolución de las nuevas tecnologías y cómo estas han cambiado el mundo. Dicha evolución es tan rápida que de un día para otro se pueden volver obsoletos los procesos u objetos tecnológicos y, por tanto, su adquisición.

Ahora bien, Rajagopal, Rajagopal y Lefkowitz (2010), por un lado, y Gil Juárez (2004), por otro, plantean que el usuario y los consumidores están influenciados por las marcas y las ubicaciones de los puntos de retail. Más allá de ello, se podrían ver los atributos y todos los contextos alrededor de los perfiles de con- sumo. Las marcas y la percepción son susceptibles de medirse, como lo afirma la investigadora Amparo Cáceres (2013, p. 151), lo cual conlleva a un posicionamiento de la imagen, la marca y la profundización en las decisiones de compra de productos, sobre todo cuando estos son de alta tecnología. Según Pike (2011), las marcas y el posicionamiento sensibilizan al consumidor que las ubica dentro de un espacio y contexto, con una imagen preconcebida producto de los clúster y la construcción de marcas.

Al profundizar en dichos autores, surgen preguntas importantes, como las expuestas a continuación, relacionadas con los consumidores ante los centros de distribución objetos de estudio. ¿Cómo percibe el consumidor estos centros de venta de alta tecnología, accesorios, suministros y gadget? ¿Tiene claridad competitiva entre lo que es un centro de alta tecnología, como el CAT, Unilago, y un almacén de de venta al por menor de estos elementos, como Ktronix o almacenes de grandes superficies que tienen sección o departamento de alta tecnología, Carrefour, hoy Jumbo, Falabella, Éxito, Panamericana, que no ofrecen garantías extendidas como San Andresito y Unilago? ¿Qué percibe y almacena en su mente el cliente con respecto a ello?

Heale Matthew (2008, p. 22) hace observaciones muy apropiadas sobre el diseño y la construcción de la marca. Él observó que en los espacios de retail se va construyendo toda una experiencia en torno a las emisiones y vivencias de los consumidores. El estilo, la visualización y los empaques hacen parte del crecimiento del negocio, así como la gestión de los espacios y del posicionamiento de los tipos de tecnologías guardadas en la mente del consumidor. Por su parte, Franzen Moriarty (2009, p. 228) conciben la posición y la marca como una arquitectura y el portafolio de construcción de marca, identificando variables en el micromercado como la fidelidad, la lealtad a la hora de comprar. Ven la marca como el estudio de los perfiles de consumo y la ciencia que hay detrás de todo 
esto. Vale la pena mencionar que con ello se estudia la interactividad de las marcas para ver su incidencia en la percepción y compra definida, por encima del precio final que se oferta o que se promociona.

Con el fin de profundizar en los tipos de perfiles y las formas de percepción de compra de los clientes a estudiar, se recurrió a autores que ahondaron en la definición de tales aspectos. Por ejemplo, Clifton (2009, p. 45) propone que los perfiles de consumo se pueden diferenciar de acuerdo con números de referencia o, lo que ella llama "the social value of Brand", es decir, el primero donde se financian y se construye la marca, se asocian las marcas, según Chances and Restrictions of Measuring Consumer Behavior in the Automotive escrito por Ray Wright (2006) si abordamos a Kardes F, Frank R. y otros (2010, p. 35) las decisiones de compra se crean desde la piscología diferentes perfiles de consumo de acuerdo a los factores y referencias segmentadas, Arellano R (2006) así también lo referencia, por lo tanto los avances tecnológicos van de la mano con estos cambios en las decisiones de compra y el intercambio de la globalización económica y cultural de un país.

La relación permanente con tecnologías implica facilidad en la realización de las tareas, puesto que tales herramientas brindan accesibilidad a diversas fuentes de información, procesamientos rápidos y fiables de cualquier tipo de datos; también generan canales de comunicación inmediata, permiten la digitalización de todo tipo de información e influyen en la evolución de la sociedad. En Colombia, aunque hay un incremento de la infraestructura tecnológica, se ha presentado un modelo de competitividad para los centros de venta al detal de altas tecnologías que ha conducido al decrecimiento en las ventas en cada uno de ellos. Por tal razón, se hizo necesario evaluar el funcionamiento del mercadeo de los productos de alta tecnología e identificar cuáles son las variables de consumo, con el propósito de establecer posibles soluciones que garanticen un mejoramiento en la percepción, un crecimiento en el consumo de unidades y, por ende, un aumento de las ventas.

\section{Método y técnicas para la recolec- ción de la información}

La investigación se llevó a cabo por parte del grupo GICEA, que se propuso estudiar y determinar las variables que se pudieran medir en cuanto a posicionamiento, percepciones de marca, perfiles determinados 1, 2, 3 y 4 del consumidor, así como detallar las razones de compra y preferencias en los centros de venta de alta tecnología y gadget. Se observó y describió el verdadero comportamiento de este tipo de clientes con el fin de despejar variables como la participación de marcas, productos bandera, ventas promedio, mayoristas preferidos y razones de elección. La base del estudio se conformó con los habituales consumidores de alta tecnología y gadgets de los estratos 2 al 5, en grupos homogéneos entre 10 y 12 personas de Bogotá que asisten a dichos centros de retail para hacer sus compras. La medida de los perfiles se hizo a partir de las preferencias de calidad en la entrega, compromiso del proveedor, terminado de producto, garantía, percepción a la hora de comprar, lealtad frente al proceso de la compra y fidelidad frente a las ventajas que le da comprar en ese sitio, precio, formas de pago y cercanía. Se tuvo como referencia, también, un mínimo de seis personas de un grupo focal de comerciantes del Centro de Alta Tecnología. Los modelos de atención, gerencia del servicio, valor de uso de estas nuevas tecnologías, percepción y capacitación de los administradores y personas interesadas en el tema, tal como lo plantean Malhotra N. (2010) y Malhotra, Birks y Wills $(2012$, caps. 6,7$)$ Son aspectos que hacen parte del proceso de la compra.

Para el levantamiento de la información se utilizó la metodología descriptiva, mediante instrumentos y análisis estructural de los sectores estratégicos previstos, según la AESE, y aplicados a centros de venta 
de tecnología, accesorios y gadgets. La medición se realizó en grandes, medianas y pequeñas superficies de venta al por menor. Se incluyó prueba de mercado y aplicación de modelos de cuestionarios. Además, se hizo una sensibilización a los estudiantes del semillero "Sesea", del programa Profesional en Mercadeo y Publicidad de la Escuela Colombiana de Carreras Industriales (ECCI Todo el proceso se llevó a cabo bajo la supervisión del grupo GICEA y de los autores de la propuesta.

El tipo de muestreo se hizo probabilístico, con elementos de la población que tuvieron la misma probabilidad de ser incluidos en la muestra aleatoria sistemática. Esta consistió en dividir la población en n estratos, compuestos por las primeras $\mathrm{K}$ de unidades, las segundas $\mathbf{k}$ unidades y así sucesivamente. En la determinación del tamaño de la muestra se manejaron varios aspectos relacionados con el parámetro y estimador, el sesgo, el error muestral, el nivel de confianza y la varianza poblacional.

El parámetro se refiere a la característica de la población objeto de estudio; el estimador es la función de la muestra que se usó para medirlo. Margen de seguridad del 95\%, Z $\alpha=1,96$; seguridad del $99 \%$, $Z \alpha$ $=2,58$. (Estos valores provienen de las tablas de la distribución normal Z, Malhotra N. (2010, p. 191) y Spiegel, A (1991, p. 3).

Se realizó un análisis exhaustivo del comportamiento de los compradores, observados en los centros de alta tecnología, de los perfiles de compra para los distribuidores, según los perfiles por grupos objetivo. Estos se especificaron así: Grupo Objetivo Uno, para los estratos socioeconómicos 2 y 3; Grupo Objetivo Dos, estratos socioeconómicos 3 y 4; Grupo Objetivo Tres, estratos 4 y 5; Grupo Objetivo Cuatro, estratos 5 y 6 . Se ubicaron también los respectivos grupos focales y sus situaciones hipotéticas con las diferentes asociaciones de las marcas preferidas en la compra así como una asociación de lugares. Se implementaron los respectivos foros y debates, luego se maneja- ron tres sesiones de acuerdo con el Perfil 1 —estratos 2 y 3 Sur (10 - 12 personas)—, tres sesiones para el Perfil 2 - estratos 3 y 4 Norte (10 - 12 personas)-, tres sesiones para consumidores del Centro de Alta Tecnología (10 - 12 Personas).

La muestra extraída de la población objeto se conformó de varias formas: dada la fórmula de proporción poblacional: $\mathrm{n}=\mathrm{Z}_{2} \mathrm{P} \mathrm{Q} / \mathrm{e}$, se obtuvo $\mathrm{Z}_{2}=1,96$ $\mathrm{P}=0,05 ; \mathrm{e}=0,02 ; \mathrm{Q}=1-0,05$ para los consumidores del sector retail que venden productos de alta tecnología y secciones de las grandes superficies que así mismo lo hacen:

$$
\frac{n=N * Z a^{2} * p * q}{d^{2 *}(N-1)+Z a^{2 *} p * q}
$$

Donde $\mathrm{N}$ es el tamaño de la población; $Z$, el nivel de confianza; p, la probabilidad de éxito; q, el fracaso; d, la precisión. Si se espera un nivel de seguridad del $95 \%$, con una precisión del $3 \%$, la proporción esperada para el $5 \%$ aproximadamente de 15.000 establecimientos, se utilizaría un valor de $p=0,5(50 \%)$ que maximiza el tamaño de la muestra. Así, pues, el valor de $\mathbf{n}$ resultó 200 :

$$
\frac{\mathrm{n}=15.000 * 1,962 * 0,05 * 0,95=200}{0,032 *(15.000-1)+1,962 * 0,05 * 0,95}
$$

\section{Estado de resultados previstos}

En el lapso de tres años (2010 - 2013), Colombia se ha convertido en un campo de inversión de grandes cadenas de supermercados de ventas al detal que se proyectan en América Latina y buscan una oportunidad de negocio. El fenómeno que empezó en Inglaterra y Estados Unidos a mediados del siglo XIX es ahora un boom en América Latina, especialmente en un país que fue inexplorado para ellos en las década anteriores. En ese contexto, la ciudad de Bogotá hace parte de tal proceso. 
En el ámbito mundial, la crisis económica afectó la venta de productos de alta tecnología entre los años 2010 y 2013; sin embargo, con la recuperación, el mercado ha mejorado constantemente a partir de dicho periodo. El negocio de la venta al por menor ha crecido en América Latina, según el informe 15 de Deloitte 2011; tal vez se configura una tendencia de expansión en los países con mercados emergentes, incluidos los de Suramérica, como Brasil, Argentina, Chile, Perú y Colombia. Su crecimiento ha sido constante en los últimos tres años, pues de los 250 de la lista de las principales firmas, 147 operan en más de un país $y$, de estos, 115 están ubicados en más de una área de la región como Sudamérica. Esto ha logrado que los modelos nuevos de competitividad se incrementen entre los centros de venta de productos de Alta tecnología tipo CAT y Unilago, los centros especializados de retail como los de Ktronix, Carrefour hoy almacenes Jumbo, Falabella y Éxito, entre otros que incursionan como los especializados, tipo papelerías Panamericana, La Polar y Ripley.

Según Berman (2007a) y Brennan (2007b), las estrategias de concentración y competencia en la distribución a través de puntos de venta al detal en el mundo comenzaron a implementarse a finales de la década pasada. Stern, El-Ansary, Couglan y Cruz (1999, p. 137) y Stephanie (2013, p. 5) también lo referencian con el tema retailers are increasingly becoming global latin american retailers in us trillion. Allí hacen referencia a las estructuras de canales de comercialización y su crecimiento a través de este mercado, entrando a Latinoamérica con gran fuerza. En la dinámica de las tendencias internacionales, estos modelos de inversión se expanden en todos los países suramericanos, incluida Colombia. El Distrito Capital presenta en la actualidad una concentración aún baja de retail si se compara con los estándares internacionales en ciudades latinoamericanas como
México DF, Monterrey, São Paulo, Buenos Aires y Santiago de Chile, donde el impacto tecnológico ha sido relevante desde principios del milenio.

Los estudios económicos realizados por Rodríguez y Vargas en 2006 y por Gamboa en 2010 muestran que el uso de nuevas tecnologías sigue en franco ascenso. Así lo demuestran los resultados y las nuevas capacidades tecnológicas en innovación y competitividad en la industria de Bogotá y Cundinamarca, como soporte, también, del desarrollo de las locomotoras de la innovación impulsadas por el Ministerio de Educación Nacional y la apuesta a las investigaciones de I+D+l propuestas en los modelos de innovación tecnológica y aplicada según el circulo de UNE 166002, NTS ISO 5801 y los resultados de las encuestas de innovación desarrolladas por la Cámara de Comercio de Bogotá, el Observatorio Colombiano de Ciencia y Tecnología y el Fondo Cultural Javeriano de Artes Gráficas.

En el manual de Schroeder (2010, p. 57), Specialty, shop retailing, como concepto perfecto, ella argumenta el uso del "Store planning/design" o diseño de tiendas modernas con nuevos conceptos de categoría, donde el layout es complejo. El manejo del inventario, la medida en la rotación y la rentabilidad de productos en los lineales, a través del facing y el planning, se ha convertido en prácticas altamente calificadoras de diferenciación, lo que ha llevado a desarrollar cambios en la percepción de los consumidores y, por lo tanto, una nueva forma de comprar en espacios llenos de color, publicidad y diseño.

La tabla 3 permite formarse una idea de los resultados de las 200 encuestas llevadas a cabo en los respectivos locales de los centros de alta tecnología, tipo CAT, Unilago, y en otros centros de ventas al por menor. 
Tabla 3. Participación por segmentos de Centros de Alta Tecnología y puntos de ventas al detal

\begin{tabular}{|l|c|c|c|}
\multicolumn{1}{|c|}{ SEGMENTOS ESTUDIADOS } & UNIVERSO & PARTICIPACIÓN & MUESTRA \\
\hline Usuario de tecnología Sector Sur de la ciudad & 3.663 .864 & $62,70 \%$ & 240 \\
\hline $\begin{array}{l}\text { Usuario de tecnología Sector Norte de la } \\
\text { ciudad }\end{array}$ & 2.178 .428 & $37,30 \%$ & 144 \\
\hline $\begin{array}{l}\text { Usuarios de tecnología que se encuentran en } \\
\text { el CAT, Unilago y otros como San Andresito }\end{array}$ & \multicolumn{2}{|c|}{ No determinado } & 100 \\
\hline TOTAL COMPORTAMIENTO & 5.842 .292 & $100 \%$ & 484 \\
\hline
\end{tabular}

Fuente: Cálculo del diario La República, según los negocios y la economía en los próximos 60 años.

La tabla 4 muestra los resultados del estudio, de acuerdo con los perfiles y la procedencia de los usuarios, sean del Norte, Centro o Sur de la ciudad, que refieren compras en el Centro de Alta Tecnología y en Unilago o en los centros especializados de ventas al detal.

Tabla 4. Resultados encontrados de acuerdo a tipos de objetivos propuestos

\begin{tabular}{|c|c|c|}
\hline PERFIL & HALLAZGOS CUANTITATIVOS & HALLAZGOS CUALITATIVOS \\
\hline & $\begin{array}{l}56 \% \text { piensa que en el CAT se paga en } \\
\text { efectivo, } 28 \% \text { reconoce las tarjetas } \\
\text { de crédito. } \\
45,5 \% \text { piensa que reciben todos los } \\
\text { métodos de pago. }\end{array}$ & $\begin{array}{l}\text { En Unilago, el pago con tarjeta de crédito es el método más conocido, } \\
\text { además del efectivo. } \\
\text { Al ser el CAT desconocido y percibido como Unilago, cuando relacionan la } \\
\text { forma de pago, señalan que efectivo y tarjeta de crédito, pero no referen- } \\
\text { cian otras como en los Retail. }\end{array}$ \\
\hline & $\begin{array}{l}54 \% \text { piensa que en el CAT se paga en } \\
\text { efectivo, } 24 \% \text { reconoce las tarjetas } \\
\text { de crédito. } \\
46 \% \text { piensa que reciben todos los mé- } \\
\text { todos de pago. }\end{array}$ & $\begin{array}{l}\text { Si supieran que existen más facilidades de pago, considerarían ir más al } \\
\text { Centro de Alta Tecnología. } \\
\text { Este perfil manifestó que si supieran de todos los métodos de pago, lo } \\
\text { tendrían más presente ysus modelos de compra seguirían allí. } \\
\text { Nota: Hubo una persona que especificó que pagaba con cheques, lo que } \\
\text { indica que sí conoce más facilidades aparte de la tarjeta de crédito y efec- } \\
\text { tivo. }\end{array}$ \\
\hline & $\begin{array}{l}\mathbf{4 4 \%} \text { identifica el efectivo como mé- } \\
\text { todo de pago pero solamente un } 6,7 \\
\text { identifica la tarjeta de crédito. } \\
52 \% \text { afirma que se reciben todos los } \\
\text { métodos de pago. }\end{array}$ & $\begin{array}{l}\text { Aunque prefieren pagar en efectivo, la mayoría tiene conocimiento de los } \\
\text { diferentes métodos de pago, pero no los tiene en cuenta a la hora de pa- } \\
\text { gar; predomina la forma de efectivo con } 8 \text { de cada } \mathbf{1 1 .}\end{array}$ \\
\hline
\end{tabular}


Tabla 5. Resultados para la propuesta de la investigación según Objetivo 2

\begin{tabular}{|c|c|c|}
\hline PERFIL & HALLAZGOS CUANTITATIVOS & HALLAZGOS CUALITATIVOS \\
\hline & 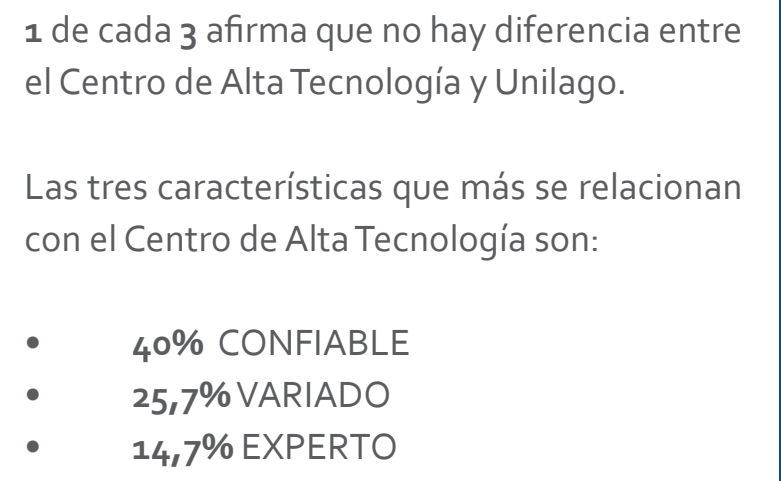 & $\begin{array}{l}\text { Tienen una percepción parcial de que Uni- } \\
\text { lago y San Andresito se parecen. } \\
\text { Como este perfil percibe al Centro de Alta } \\
\text { Tecnología como Unilago, indirectamen- } \\
\text { te se infiere que al considerar a Unilago } \\
\text { como parecido a San Andresito, también } \\
\text { están relacionando al CAT. (Véase gráfi- } \\
\text { cos } 1 \text { y 2.) }\end{array}$ \\
\hline & $\begin{array}{l}\text { - En orden importancia, la marca Centro de } \\
\text { Alta Tecnología es relacionada con: } \\
\text { - Confiabilidad } 39 \% \\
\text { - Variedad } 30 \% \\
\text { - Experto } 11 \% \\
\text { - Originalidad } 8,5 \% \\
\text { - Unilago se relaciona con: } \\
\text { - Variedad } 47 \% \\
\text { - Barato } 21,5 \% \\
\text { - Pirata } 12 \% \\
\text { - Experto } 9 \%\end{array}$ & $\begin{array}{l}\text { Menos piensan que Unilago y San Andre- } \\
\text { sito se parecen. } \\
\text { Al tener un mayor conocimiento de Unila- } \\
\text { go y el CAT, la relación con San Andresito } \\
\text { disminuye, pero sigue existiendo, por las } \\
\text { características comunes entre los dos. } \\
\text { (Gráfica 3) } \\
\text { Tienen presentes los centros de venta de } \\
\text { productos de alta tecnología diferentes a } \\
\text { CAT, San Andresito y Unilago. }\end{array}$ \\
\hline & $\begin{array}{l}\text { El } 31 \% \text { no percibe diferencia entre los dos cen- } \\
\text { tros comerciales. (Véase gráfica } 4 \text { ) } \\
\text { - Las principales características que se aso- } \\
\text { cian con Unilago son: } \\
\text { - Variedad } 38 \% \\
\text { - Piratería } 20 \% \\
\text { - Barato } 13 \% \\
\text { - Experto } 10 \% \text { (Gráfica 5) }\end{array}$ & $\begin{array}{l}\text { Este perfil no relaciona a Unilago (y } \\
\text { por ende al CAT) con San Andresito. } \\
\text { Aunque siguen hablando sobre la relación } \\
\text { que tienen por las características en co- } \\
\text { mún, no lo consideran igual como en los } \\
\text { anteriores perfiles. } \\
\text { (Gráfica 6) [No aparece] }\end{array}$ \\
\hline
\end{tabular}


Tabla 6. Resultados cualitativos para la propuesta de la investigación según Objetivo 3

\begin{tabular}{|c|c|}
\hline $\begin{array}{l}P_{1}, P_{2} \\
y P_{3}\end{array}$ & $\begin{array}{l}\text { - Para la mayoría predomina la marca por encima del precio. } \\
\text { - Es decir, los centros de alta tecnología localizados en grandes marcas o cadenas } \\
\text { - Falabella, Carrefour, Éxito, K Tronix son sus preferentes para las compras, por la } \\
\text { facilidad de pago, la comodidad en la compra pero sobre todo por la seguridad en } \\
\text { el desplazamiento y la acción de la compra. }\end{array}$ \\
\hline $\begin{array}{c}\text { Resultados } \\
\text { Cualitativos } \\
\qquad \mathrm{P}_{1}\end{array}$ & $\begin{array}{l}\text { - Las marcas predilectas de los consumidores de tecnología son: } \\
\text { Casa: Hp/Clon } \\
\text { Oficina: Hp/Dell } \\
\text { - El gasto promedio de los consumidores es : } \\
\text { Casa: } \$ 800.000-\$ 3.500 .000 \\
\text { Oficina: } \$ 900.000-\$ 4.000 .000 \\
\text { NOTA: Los costos altos en computadores es por compra de máquinas especiali- } \\
\text { zadas. } \\
\text { A la hora de comprar computador, usted prefiere: }\end{array}$ \\
\hline $\begin{array}{c}\text { Resultados } \\
\text { Cualitativos } \\
\qquad \mathrm{P}_{2}\end{array}$ & $\begin{array}{l}\text { - Las marcas predilectas de los consumidores de tecnología son: } \\
\text { Casa: Hp/Dell/Toshiba } \\
\text { Oficina: Hp/Dell } \\
\text { - El gasto promedio de los consumidores en computadores es: } \\
\text { Casa: } \$ 700.000-\$ 5.000 .000 \\
\text { Oficina: } \$ 1.000 .000-\$ 8.000 .000 \\
\text { - NOTA: Los costos altos en computadores es por compra de máquinas especiali- } \\
\text { zadas. }\end{array}$ \\
\hline $\begin{array}{c}\text { Resultados } \\
\text { Cualitativos } \\
\mathrm{P}_{3}\end{array}$ & $\begin{array}{l}\text { - Las decisiones de compra están dados por la facilidad en vías de comunicación, en } \\
\text { parqueo, cargue y descargue y por las opciones de pago que incluyen financiación }\end{array}$ \\
\hline $\begin{array}{c}\text { Resultados } \\
\text { Cualitativos se- } \\
\text { gún objetivos } \\
\mathrm{No}_{4}\end{array}$ & $\begin{array}{l}\text { Las marcas predilectas de los consumidores de tecnología son: } \\
\text { Casa: Hp/Dell/Toshiba } \\
\text { Oficina: Hp/Dell } \\
\text { - El gasto promedio de los consumidores en computadores es: } \\
\text { Casa: } \$ 1.700 .000-\$ 6.000 .000 \\
\text { Oficina: } \$ 2.000 .000-\$ 10.000 .000 \\
\text { - NOTA: Los costos altos en computadores es por compra de máquinas especializa- } \\
\text { das. Y su compra es preferente en los centros comerciales y los centro especializa- } \\
\text { dos de retail tipo Falabella, KTronix y grandes cadenas de distribución. }\end{array}$ \\
\hline
\end{tabular}




\section{Aspectos relevantes que se observa- ron:}

- Un análisis exhaustivo, con pormenores y ponderados, arrojó los siguientes resultados: El $24,9 \%$ de los consumidores perciben que los centros de alta tecnología especializados son más económicos que los almacenes de cadena; es decir, CAT y Unilago vs los otros objetos de estudio. El $24,4 \%$ de los usuarios afirma que los almacenes de cadena que venden tecnología son más caros; por el contrario, en los almacenes de cadena, el 3,8\% afirma que estos son más baratos por ser mayoristas. El 36,3\% afirma que el CAT presta mejor asesoría, mientras que el $32,1 \%$ dice que el CAT y Unilago prestan la misma asesoría, y el 3,3\% manifiesta que Unilago presta mejor asesoría.

- En cuanto a la variedad de productos, las encuestas lograron establecer que la percepción del $52,8 \%$ determina que CAT y Unilago tienen la misma variedad de productos, el 53,1\% afirma que el CAT es mejor que Unilago porque tiene mejor estructura y ambiente y el $5,8 \%$ dice que el CAT y Unilago son iguales. El 26,1\% determinó que el CAT es un sitio a la vanguardia, comparándolo con otros centros de alta tecnología. El 51,2\% afirmó que los centros comerciales han crecido mucho y están a la vanguardia, pues allí se consigue lo último; el $28,1 \%$ dice que es un sitio donde se consigue todo en tecnología y el $7,4 \%$ afirma que es un sitio que vende lo mismo que los almacenes de cadena pero más barato.

- Al examinar las visitas a los centro comerciales y a los centros de venta de productos de alta tecnología, se verificó que tales visitas ocurren de acuerdo con los estratos socioeconómicos: quienes más asisten a los centros comerciales pertenecen al estrato 4 , con un $87,5 \%$, mientras el $22,0 \%$ de los estratos 2 y 3 corresponde a quienes más asisten a los centros de alta tecnología, pues buscan precio, promociones y descuentos a cambio de comodidad, seguridad y vías de comunicación.
- También se demostró el siguiente comportamiento por estratos: las personas de estrato 2 y 3 , mayoritariamente, en un $68,9 \%$, se fijan principalmente en el precio; el $11,2 \%$, en la marca, y el 1,5\%, en la calidad. La diversidad de productos que se muestran es relevante: hasta un $30,8 \%$ busca variedad, el $28,2 \%$, los mismos productos comparativos del retail, en centros comerciales, pero a precios menores, y solo el $0,5 \%$ busca realmente el buen servicio.

- Por edades de los compradores, la relación es como sigue: entre 25 y 40 años, el 36\%; entre 18 y 25 años, el $23 \%$, y los menores de 18 años ascienden al 19\%; es decir, la población mayor es la que toma decisiones de compra en los centro de venta de alta tecnologías y gadget. Adicionalmente, la variedad de productos hace que los clientes sean frecuentes en un $60 \%$ y clientes nuevos en un $40 \%$.

- Los programas de relación con los clientes (CRM) y fidelización de estos, implementados por los negocios objeto de estudio, son bajos y débiles en los centros de alta tecnología pero aplicados y formativos en los centros comerciales y en las zonas de tecnología de los grandes retail. Es decir, el $81 \%$ de los consumidores dice no conocerlos y no verlos aplicados en los centros de alta tecnología, pero el $19 \%$ dice sí conocerlos y percibir su aplicación en los puntos de tecnología de los centros comerciales.

- La labor del departamento de mercadeo se mira como algo sin importancia en los centros de alta tecnología. Sus calificaciones estuvieron por debajo del $35,7 \%$ para las estrategias que se aplican y de $26,1 \%$ de desconocimiento de las labores desempeñadas; solo el 1,5\% aprobó como buena la aplicación en los casos del CAT y Unilago. En el caso de los centros comerciales y retail especializados, esta percepción es absolutamente diferente. 
La tabla 7 permite apreciar los indicadores más sobresalientes de la investigación.

Tabla 7: Lo observado durante el proceso de levantamiento de la información

\begin{tabular}{|c|c|c|c|}
\hline OBSERVACIONES & GRUPO OBJETIVO 1 & GRUPO OBJETIVO 2 & GRUPO OBJETIVO $_{3}$ \\
\hline \multirow{4}{*}{ Formas de pago } & $\begin{array}{l}\text { El } 45 \% \text { piensa que se reci- } \\
\text { ben todas las formas de } \\
\text { pago. }\end{array}$ & & $\begin{array}{l}52 \% \text { de los encuestados } \\
\text { piensan que se reciben } \\
\text { dichas formas de pago. } \\
\text { En efectivo. }\end{array}$ \\
\hline & $\begin{array}{l}\text { El efectivo tiene la res- } \\
\text { puesta más alta: } 56 \% \text {. }\end{array}$ & & $\begin{array}{l}\text { Que pueden pagar con } \\
\text { efectivo. }\end{array}$ \\
\hline & $\begin{array}{l}\text { El } 28 \% \text { piensa que se } \\
\text { puede pagar con tarjeta } \\
\text { de crédito (Véase Sur de } \\
\text { Bogotá] }\end{array}$ & & $\begin{array}{l}\text { El } 46 \% \text {, con todas las } \\
\text { anteriores. Es decir efec- } \\
\text { tivo, crédito, tarjeta, } \\
\text { cheque. Financiación. }\end{array}$ \\
\hline & $33 \%$, cada dos años. & $\begin{array}{l}\text { El } 24 \% \text {, tarjeta de crédi- } \\
\text { to y con menor porcen- } \\
\text { taje crédito Codensa y } \\
\text { cheque (Véase gráfica } \\
\text { Sur de Bogotá) }\end{array}$ & \\
\hline \multirow[b]{2}{*}{$\begin{array}{c}\text { ¿Cada cuánto cambia } \\
\text { o actualiza su compu- } \\
\text { tador? }\end{array}$} & $31 \%$ cada año. & $\begin{array}{l}\text { El } 35 \% \text { de los encuesta- } \\
\text { dos cambia o actualiza } \\
\text { cada uno o dos años su } \\
\text { computador. }\end{array}$ & $\begin{array}{l}\text { Con menor porcentaje, } \\
\text { prefiere menos de un } \\
\text { año o cada cinco años o } \\
\text { más. }\end{array}$ \\
\hline & $\begin{array}{l}18 \% \text { menos de un año } \\
\text { (Véase gráfica sur de Bo- } \\
\text { gotá] }\end{array}$ & $\begin{array}{l}\text { Mientras un menor por- } \\
\text { centaje prefieren menos } \\
\text { de un año o cada cinco } \\
\text { años o más. (Véase grá- } \\
\text { fica sur de Bogotá] }\end{array}$ & $\begin{array}{l}\text { Gráfica Norte de Bogo- } \\
\text { tá] El } 37 \% \text { de los encues- } \\
\text { tados prefiere actualizar } \\
\text { o cambiar su computa- } \\
\text { dor cada año, seguido de } \\
\text { un } 32 \% \text { que lo hace cada } \\
\text { dos años. }\end{array}$ \\
\hline \multirow[b]{2}{*}{$\begin{array}{l}\text { Tiempo desde la últi- } \\
\text { ma vez que compró un } \\
\text { artículo de tecnología. }\end{array}$} & $\begin{array}{l}35 \% \text { de los encuestados } \\
\text { respondió que entre seis } \\
\text { meses y un año. }\end{array}$ & $\begin{array}{l}\text { El } 32 \% \text { compró un artí- } \\
\text { culo de tecnología entre } \\
\text { seis meses y un año. }\end{array}$ & $\begin{array}{l}\text { El } 49 \% \text { compró por úl- } \\
\text { tima vez un artículo de } \\
\text { tecnología hace un mes } \\
\text { o menos. }\end{array}$ \\
\hline & $\begin{array}{l}26 \% \text { responde entre tres } \\
\text { a seis meses y el } 23 \% \\
\text { entre uno a tres meses. } \\
\text { (Véase Sur de Bogotá] }\end{array}$ & $\begin{array}{l}\text { El } 29 \% \text { prefiere entre } \\
\text { tres y seis meses, con un } \\
\text { menor porcentaje entre } \\
\text { uno a tres meses o un } \\
\text { mes o menos. [Véase } \\
\text { gráfica Sur de Bogotá] }\end{array}$ & $\begin{array}{l}\text { Seguido de un } 21 \% \text { que } \\
\text { la realizo entre uno y } \\
\text { tres meses, mientras con } \\
\text { porcentajes de un } 15 \% \text {, } \\
\text { de tres a seis meses y de } \\
\text { seis a } 12 \text { meses. (Gráfica } \\
\text { Norte de Bogotá] }\end{array}$ \\
\hline
\end{tabular}




\begin{tabular}{|c|c|c|c|}
\hline \multirow{4}{*}{$\begin{array}{c}\text { La última vez que } \\
\text { compró un artículo } \\
\text { de tecnología fue una } \\
\text { compra: }\end{array}$} & $\begin{array}{l}65 \% \text {, lacompra fue pro- } \\
\text { gramada. }\end{array}$ & $\begin{array}{l}\text { El } 64 \% \text { de los encuesta- } \\
\text { dos su }\end{array}$ & El $72 \%$ hizo su compra \\
\hline & $\begin{array}{l}34 \% \text {, la compra fue ca- } \\
\text { sual. (Véase gráfica Sur } \\
\text { de Bogotá }\end{array}$ & $\begin{array}{l}\text { compra fue programa- } \\
\text { da. }\end{array}$ & programada. \\
\hline & & $\begin{array}{l}\text { Mientas para el } 35 \% \text { fue } \\
\text { una }\end{array}$ & $\begin{array}{l}\text { Frente a un } 28 \% \text { que fue } \\
\text { casual. }\end{array}$ \\
\hline & & $\begin{array}{l}\text { compra casual. (Gráfica } \\
\text { Sur de Bogotá] }\end{array}$ & $\begin{array}{l}\text { (Gráfica 34) [Norte e Bo- } \\
\text { gotá }\end{array}$ \\
\hline \multirow{5}{*}{$\begin{array}{l}\text { A la hora de comprar } \\
\text { tecnología, ¿qué es lo } \\
\text { más importante? }\end{array}$} & $\begin{array}{l}\text { 28\% prefiere un buen } \\
\text { balance marca/precio, } \\
\text { inclinado por la marca. }\end{array}$ & $\begin{array}{l}\text { El 33\% prefiere un buen } \\
\text { balance entre marca y } \\
\text { precio, inclinándose por } \\
\text { la marca. }\end{array}$ & $\begin{array}{l}\text { Marca / precio, inclinado } \\
\text { por marca. }\end{array}$ \\
\hline & $\begin{array}{l}22 \% \text { responde: definiti- } \\
\text { vamente "La marca". }\end{array}$ & $\begin{array}{l}\text { El } 27 \% \text {, definitivamente } \\
\text { la marca. }\end{array}$ & $\begin{array}{l}\text { Seguido de un } 27 \% \text { que } \\
\text { responde }\end{array}$ \\
\hline & $\begin{array}{l}\text { 19\% características tec- } \\
\text { nológicas del equipo (ver } \\
\text { Grafica sur de Bogotá] }\end{array}$ & $\begin{array}{l}\text { El } 20 \% \text {, características } \\
\text { del equipo. }\end{array}$ & $\begin{array}{l}\text { La tecnología del equipo; } \\
\text { con }\end{array}$ \\
\hline & & $\begin{array}{l}\text { Y con menor porcenta- } \\
\text { je, precio, calidad y ga- } \\
\text { rantía. (Gráfica sur de } \\
\text { Bogotá] }\end{array}$ & $\begin{array}{l}\text { menor porcentaje, la } \\
\text { marca, }\end{array}$ \\
\hline & & & $\begin{array}{l}\text { Precio, garantía y cali- } \\
\text { dad. }\end{array}$ \\
\hline \multirow{6}{*}{$\begin{array}{l}\text { Dónde compró com- } \\
\text { putador la última vez: }\end{array}$} & $24 \%$, Alkosto & $\begin{array}{l}\text { El } 21 \% \text { compró por últi- } \\
\text { ma vez computador en } \\
\text { Alkosto. }\end{array}$ & (Gráfica 35) [No aparece] \\
\hline & $17 \%$, Unilago & $\begin{array}{l}\text { El } 16 \% \text { escogió a Unila- } \\
\text { go. }\end{array}$ & $\begin{array}{l}\text { El } 43 \% \text { compró, por últi- } \\
\text { ma vez, }\end{array}$ \\
\hline & $\begin{array}{l}\text { 15\%, Carrefour (Véase } \\
\text { gráfica 12) [No aparece] }\end{array}$ & $\begin{array}{l}\text { Seguido por Carrefour, } \\
\text { con un } 13 \% \text {. }\end{array}$ & $\begin{array}{l}\text { un computador en el } \\
\text { CAT. }\end{array}$ \\
\hline & & $\begin{array}{l}\text { Mientras con menor } \\
\text { porcentaje }\end{array}$ & $\begin{array}{l}\text { Seguido de un } 24 \% \text { que } \\
\text { realizó la compra }\end{array}$ \\
\hline & & $\begin{array}{l}\text { se encuentran Éxito, K- } \\
\text { tronix }\end{array}$ & $\begin{array}{l}\text { En Unilago. Con meno- } \\
\text { res }\end{array}$ \\
\hline & & $\begin{array}{l}\text { y Falabella. (Gráfica 26) } \\
\text { [No aparece] }\end{array}$ & $\begin{array}{l}\text { porcentajes en San An- } \\
\text { dresito, }\end{array}$ \\
\hline
\end{tabular}




\begin{tabular}{|c|c|c|c|}
\hline \multirow{6}{*}{$\begin{array}{l}\text { ¿Cuál fue la razón de } \\
\text { compra en ese sitio? }\end{array}$} & $27 \%$ prefiere garantía, & El 28\% prefiere garantía & $\begin{array}{l}\text { El } 32 \% \text { Prefieren garan- } \\
\text { tía por estrato socioe- } \\
\text { conómico al que perte- } \\
\text { necen lo cual los hace } \\
\text { más perceptivos y más } \\
\text { exigentes }\end{array}$ \\
\hline & $20 \%$ prefiere precio. & $\begin{array}{l}\text { Como principal razón de } \\
\text { compra. }\end{array}$ & (Gráfica 36) [No aparece] \\
\hline & $14 \%$ prefiere calidad, & Con un $20 \%$, precio, & $\begin{array}{l}\text { La principal razón de } \\
\text { compra, }\end{array}$ \\
\hline & $\begin{array}{l}\text { 13\% promociones y cer- } \\
\text { canía. (Véase gráfica } 13 \text { ) } \\
\text { [No aparece] }\end{array}$ & $11 \%$, calidad. & $\begin{array}{l}\text { con un } 23 \% \text {, fue precio, } \\
\text { con un }\end{array}$ \\
\hline & & $\begin{array}{l}\text { Y con menor porcenta- } \\
\text { je, asesoría, respaldo y } \\
\text { recomendación. (Gráfi- } \\
\text { ca norte de Bogotá }\end{array}$ & $\begin{array}{l}21 \% \text {, calidad y con } 16 \% \text {, } \\
\text { garantía (Gráfica norte } \\
\text { de Bogotá }\end{array}$ \\
\hline & $\begin{array}{l}28 \% \text { responde } \mathrm{HP} \text {, como } \\
\text { la principal marca prefe- } \\
\text { rida. }\end{array}$ & $\begin{array}{l}\text { El } 29 \% \text { prefiere HP a la } \\
\text { hora. }\end{array}$ & \\
\hline \multirow{5}{*}{$\begin{array}{c}\text { A la hora de comprar } \\
\text { computador, usted } \\
\text { prefiere: }\end{array}$} & $23 \%$, Dell & $\begin{array}{l}\text { De comprar computa- } \\
\text { dor, }\end{array}$ & \\
\hline & 18\%, Toshiba. & $\begin{array}{l}\text { un } 23 \% \text { escoge Toshiba, } \\
\text { seguido de Dell } 18 \% \text {. }\end{array}$ & \\
\hline & $\begin{array}{l}\text { En menor porcentaje, } \\
\text { marcas como Gigabyte, } \\
\text { Samsun y Lenovo. (Véase } \\
\text { gráfica 14) [No aparece] }\end{array}$ & $11 \%$, COMPAQ. & \\
\hline & & $\begin{array}{l}\text { Con menor porcenta- } \\
\text { je, Gigabyte, Samsung } \\
\text { y Lenovo. (Gráfica 28) } \\
\text { [No aparece] }\end{array}$ & $\begin{array}{l}\text { El } 37 \% \text { prefiere Toshiba, } \\
\text { el } 18 \%\end{array}$ \\
\hline & & & HP y el $13 \%$ un clon \\
\hline
\end{tabular}




\begin{tabular}{|c|c|c|c|}
\hline \multirow{5}{*}{$\begin{array}{l}\text { La marca de su com- } \\
\text { putador es: }\end{array}$} & $26 \% \mathrm{HP}$ & $\begin{array}{l}\text { El } 33 \% \text { tienen marca } \\
\text { de computador HP, se- } \\
\text { guida con } 16 \% \text { y } 15 \% \\
\text { Dell y Toshiba, respec- } \\
\text { tivamente. } 11 \% \text {, Clon y } \\
\text { Compac. }\end{array}$ & $\begin{array}{l}\text { Mientas el menor por- } \\
\text { centaje: }\end{array}$ \\
\hline & $20 \%$ Dell & $\begin{array}{l}\text { Con menor porcentaje } \\
\text { aparecen }\end{array}$ & $\begin{array}{l}\text { Sony, Gateway, Gigaby- } \\
\text { te, }\end{array}$ \\
\hline & 12\% Toshiba & $\begin{array}{l}\text { marcas como Acer, Va- } \\
\text { nus }\end{array}$ & Samsung y Lenovo. \\
\hline & $\begin{array}{l}\text { 11\% clon. (Véase gráfica } \\
\text { sur de Bogotá) }\end{array}$ & Samsung. & $\begin{array}{l}\text { (Gráfica 38) norte de Bo- } \\
\text { gotá }\end{array}$ \\
\hline & & $\begin{array}{l}\text { Gráfica } 29 \text { sur de Bogo- } \\
\text { tá }\end{array}$ & \\
\hline \multirow{4}{*}{$\begin{array}{l}\text { A la hora de comprar } \\
\text { tecnología prefiere: }\end{array}$} & $\begin{array}{l}66 \% \text {, precios e indicacio- } \\
\text { nes, explicados y nego- } \\
\text { ciables. }\end{array}$ & $\begin{array}{l}\text { El } 61 \% \text { prefiere que los } \\
\text { precios }\end{array}$ & $\begin{array}{l}\text { Definitivamente, en un } \\
87 \% \text {, asistir a centros } \\
\text { especializados que le } \\
\text { brinden seguridad, } \\
\text { confianza y garantías } \\
\text { extendidas. }\end{array}$ \\
\hline & $\begin{array}{l}31 \%, \text { visibles pero no ne- } \\
\text { gociables. }\end{array}$ & y las indicaciones sean & $\begin{array}{l}74 \% \text { prefiere marca so- } \\
\text { bre precio. }\end{array}$ \\
\hline & $\begin{array}{l}\text { 1\%, indicaciones impre- } \\
\text { sas y negociables. (Véase } \\
\text { gráfica sur de Bogotá) }\end{array}$ & $\begin{array}{l}\text { explicados y negocia- } \\
\text { bles. }\end{array}$ & \\
\hline & & $\begin{array}{l}\text { Seguida con un } 38 \% \\
\text { que prefieren que los } \\
\text { precios y las indicacio- } \\
\text { nes sean impresas, cla- } \\
\text { ramente comunicadas } \\
\text { y no negociables. }\end{array}$ & \\
\hline $\begin{array}{l}\text { A la hora de comprar } \\
\text { tecnología, entre } \\
\text { marca y precio, usted } \\
\text { prefiere: }\end{array}$ & $\begin{array}{l}25 \% \text {, mejor precio. (Véa- } \\
\text { se gráfica sur de Bogotá) }\end{array}$ & & $\begin{array}{l}\text { Siempre, la marca } \\
\text { primero sobre el precio. } \\
\text { Es claro ver cómo } \\
\text { prefieren atención, } \\
\text { servicio y garantías } \\
\text { extendidas. }\end{array}$ \\
\hline \multirow[t]{2}{*}{$\begin{array}{c}\text { ¿Con quién va a } \\
\text { comprar tecnología? }\end{array}$} & $\begin{array}{l}39 \% \text {, acompañado por } \\
\text { familia. }\end{array}$ & & \\
\hline & $\begin{array}{l}39 \% \text {, solos. (Véase gráfi- } \\
\text { ca 18) [sur de Bogotá }\end{array}$ & & \\
\hline
\end{tabular}




\begin{tabular}{|c|l|l|l|}
\hline & $34 \%$, por la variedad. & $\begin{array}{l}\text { El 34\% de los encues- } \\
\text { tados prefieren el CAT, } \\
\text { por variedad. }\end{array}$ & $\begin{array}{l}\text { No prefieren el CAT ni } \\
\text { Unilago, por tiempo, } \\
\text { congestión, desplaza- } \\
\text { miento y comodidad. }\end{array}$ \\
\cline { 2 - 4 } $\begin{array}{c}\text { vez de ir a un almacén } \\
\text { de cadena porque: }\end{array}$ & $30 \%$, por mejor asesoría. & $\begin{array}{l}24 \%, \text { mejores precios y } \\
\text { mejor asesoría. (Véase } \\
\text { gráfica 21) }\end{array}$ & $\begin{array}{l}\text { Definitivamente, San } \\
\text { Andresito no es un sitio } \\
\text { para comprar tecnolo- } \\
\text { gía. }\end{array}$ \\
\cline { 2 - 4 } & $\begin{array}{l}\text { 18\%, se consiguen mejo- } \\
\text { res precios. (Véase gráfi- } \\
\text { ca 19) sur de Bogotá }\end{array}$ & & \\
\hline
\end{tabular}

Tabla 8. Resultados cuantitativos por perfiles. Grupo Objetivo 4 para casos de estudios

- Las principales marcas que se prefieren son Toshiba

$(56,3 \%)$, Sony $(34,4 \%)$ y HP $(28,1 \%)$.

- Los clientes suelen ir a comprar accesorios (cámara web, parlantes, micrófonos de exterior, tabla digitalizadora.)

$42,4 \%$, a comprar portátil; un $24,2 \%$ compras cámaras para web, y solo un $3 \%$ compran cámara digital.

- Los segundos productos que más les importa vender son

computadores de escritorio, con un porcentaje de $22,7 \%$ y el $28 \%$ de locales los venden.

- El tercer producto que más les importa vender son

portátiles con $29,4 \%$ y un porcentaje de venta de $15 \%$.

- La marca que más venden los locales es

HP, con un porcentaje de $20,8 \%$ y una participación de $52 \%$, la segunda marca es Toshiba con $28,6 \%$ y participación de ventas de $26 \%$; la tercera marca son Genius y Acer, con $10 \%$, y participación de $20 \%$.

- Las tres marcas principales con las que prefieren trabajar los locales son

Toshiba, 37,0\%; Acer, 22,2\%, y Sony, 25,9\%, el otro $14,9 \%$ prefiere comprar otras marcas

- Los dueños de los locales prefieren trabajar con estas marcas principalmente por

su alta rotación, 32,1\%; por la garantía que prestan, 21,4\%; por su confiabilidad, $17,9 \%$, y por su respaldo, $10,7 \%$. 
- De los proveedores más utilizados está
MPS, $22,7 \%$, con una participación de ventas mensuales aproximadamente de $\$ 18.175 .000$. El segundo proveedor más utilizado es POLUX, con un $22,2 \%$ y una participación de ventas mensuales aproximadamente de $\$ 8.605 .000$, y los terceros proveedores más utilizados son MACROCOMPUTO y MOUSESTAR, con 14,3\% y una participación de ventas mensuales aproximadamente de $\$ 8.137 .500$.
PARECIDOS

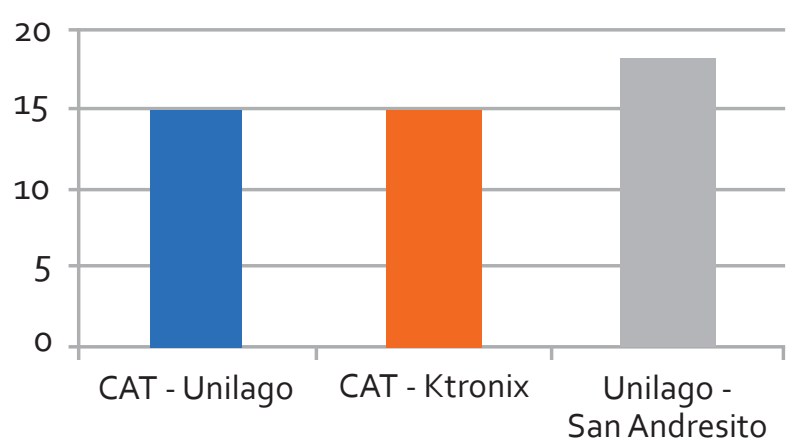

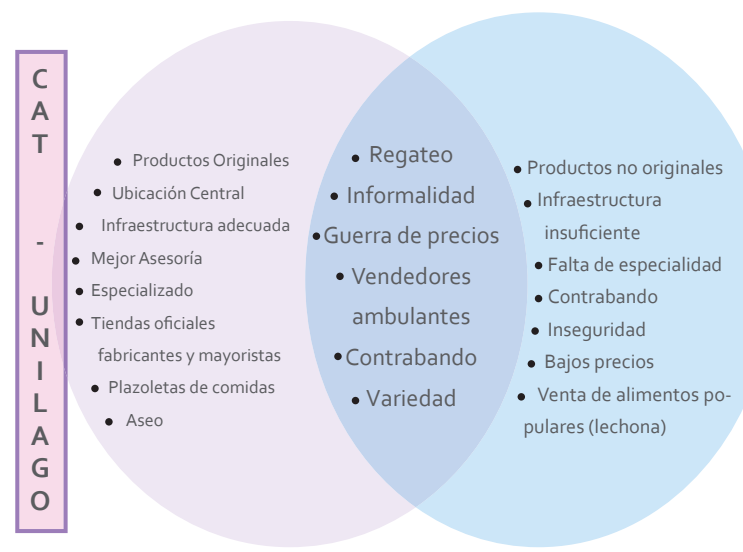

Figura 1. Comportamientos de las diferentes áreas en superficies, de acuerdo con perfiles de comportamiento. Objetivo 1 Fuente: Elaboración propia.

PARECIDOS

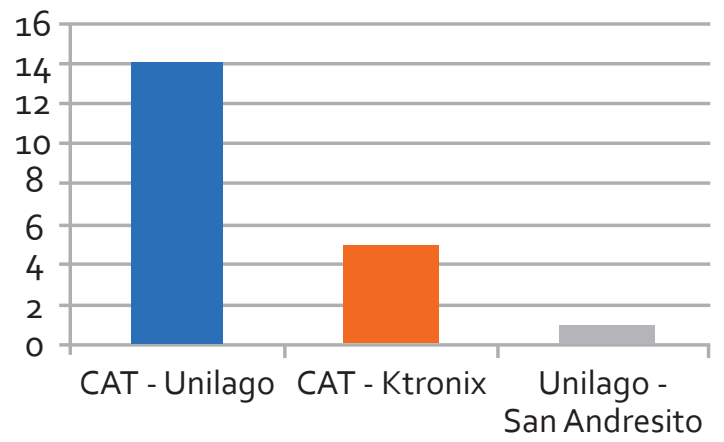

PARECIDOS

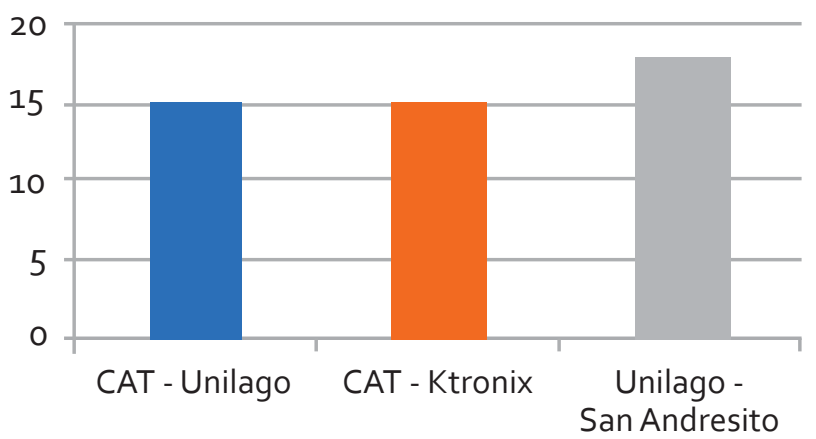

Figura 2. Comportamientos de las diferentes áreas en superficies de acuerdo con perfiles de comportamiento. Objetivos 2 y 3 Fuente: Elaboración propia. 
PERFIL 1

DESCONOCIDO

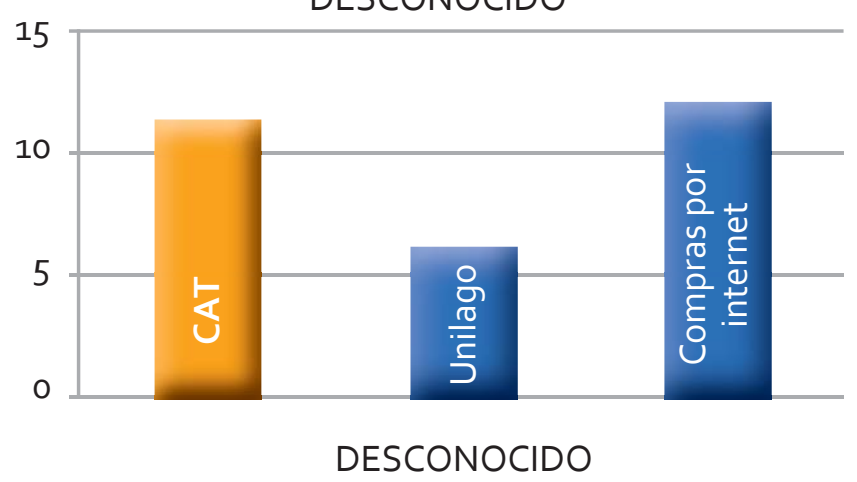

PERFIL 2

DESCONOCIDO

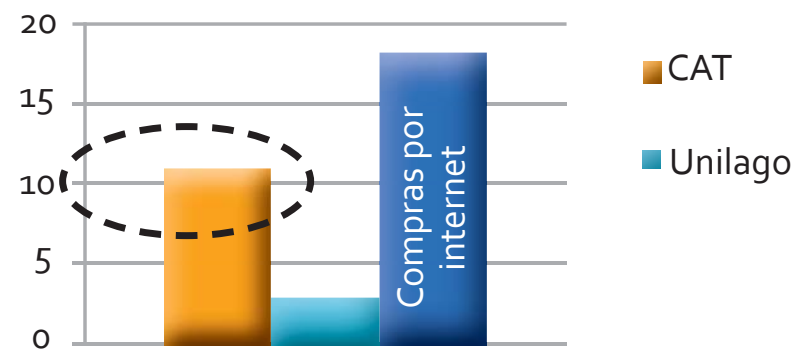

Figura 3: Comportamientos de las diferentes áreas en superficies de acuerdo con perfiles de comportamiento según: Objetivos 1, 2 y 3 Fuente: Elaboración propia.

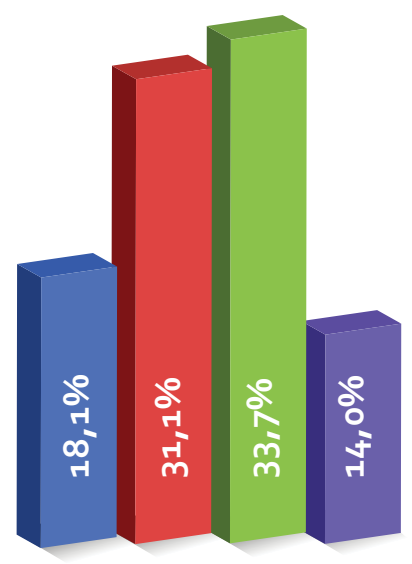

SUR

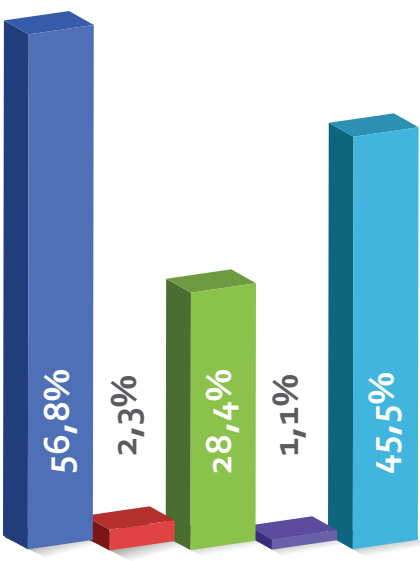

SUR

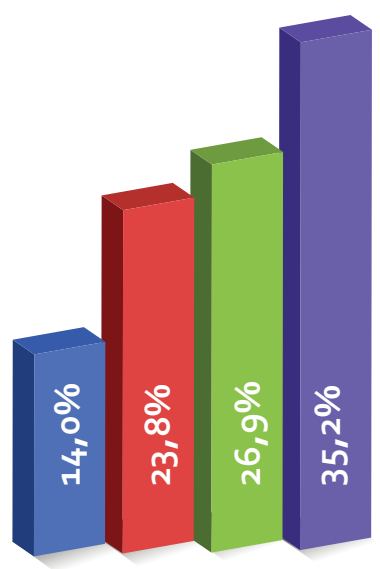

SUR

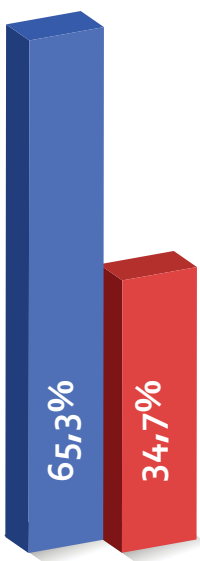

SUR

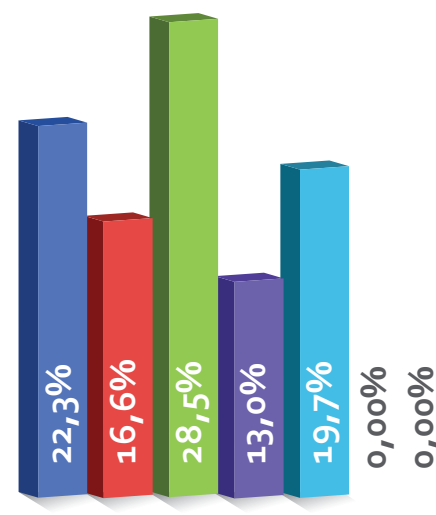

SUR

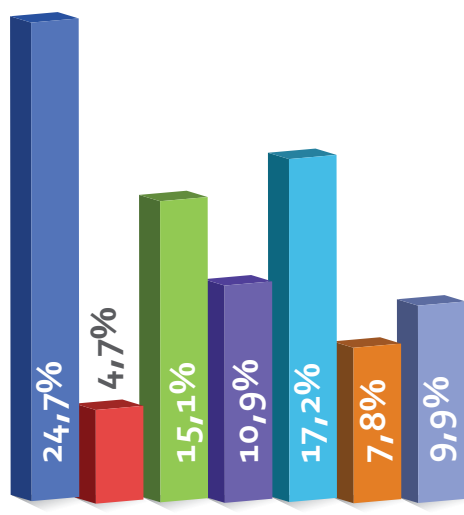

SUR

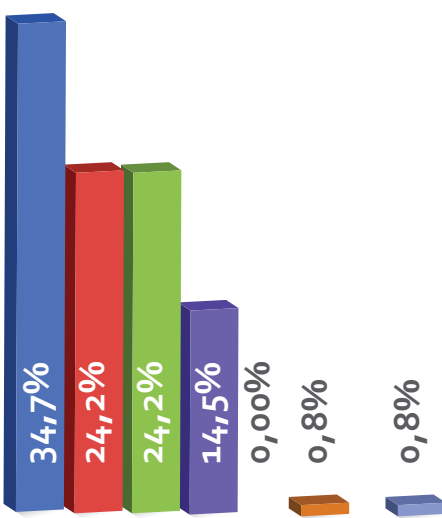

NORTE 


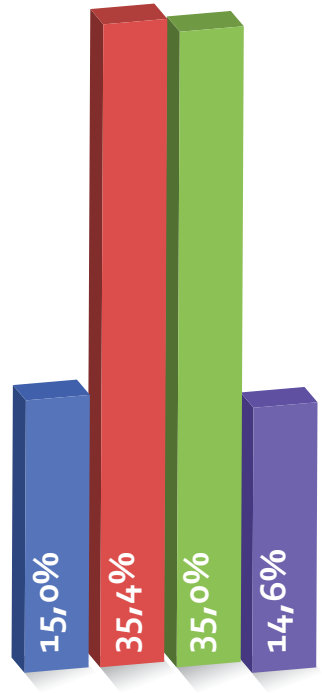

NORTE

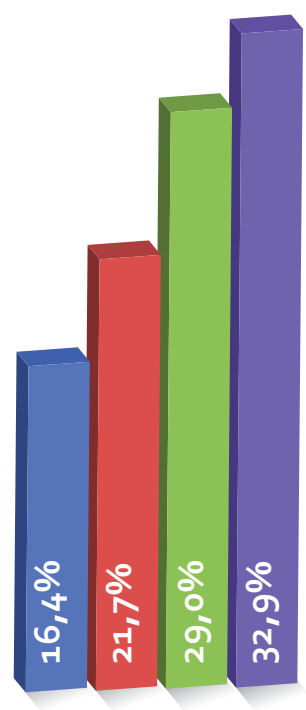

NORTE

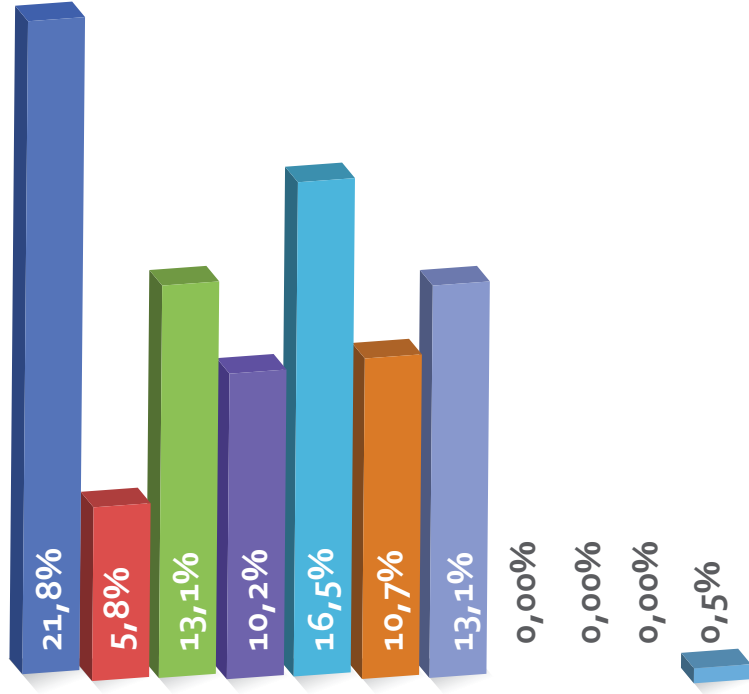

NORTE

Figura 4. Comportamientos de las diferentes áreas Observadas como formas de pago, cada cuánto cambia o actualiza su computador, Tiempo desde la última vez que compró un artículo de tecnología. Para los sectores de la ciudad Bogotá.

Fuente: Elaboración propia.

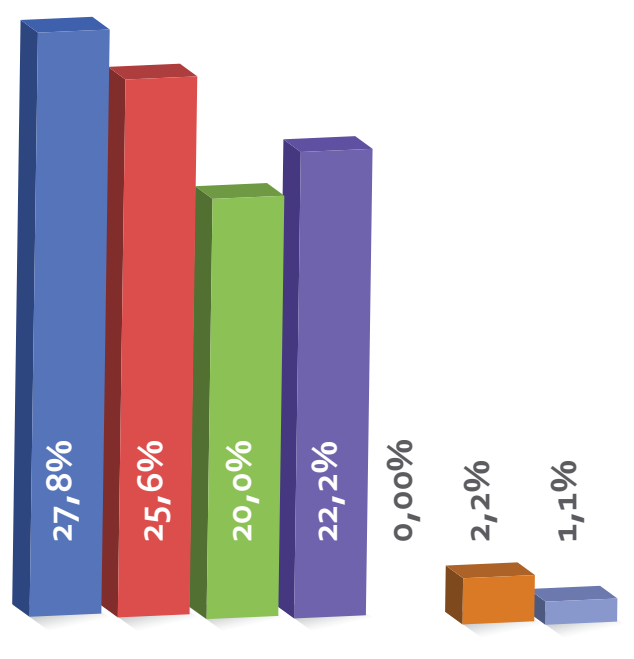

PORQUE ES MÁS VARIADO

PORQUE PUEDO CONSEGUIR MEJORES PRECIOS

POROUE OBTENGO MEJOR ASESORÍA

PORQUE EXPERTO

SIEMPRE COMPRO EL MISMO PRODUCTO "ANTIVIRUS" POR CALIDAD

CONFIANZA EN EL ASESOR

PRECIOS / BUENOS PRECIOS

Figura 5. Comportamientos de las diferentes áreas observadas en precios, variedades, calidad para el CAT en la ciudad de Bogotá Fuente: Elaboración propia. 

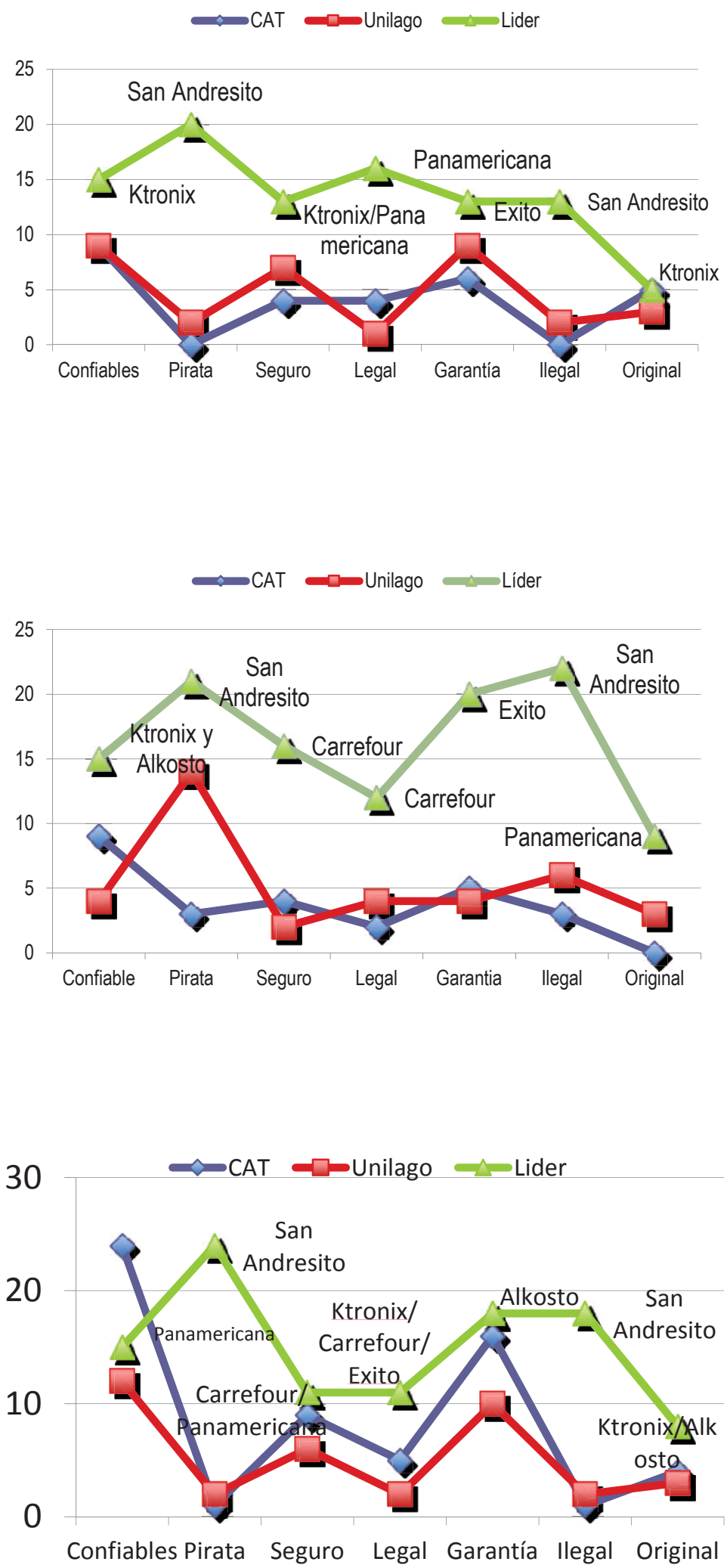

Figura 6. Comportamientos de las diferentes áreas en superficies de acuerdo con perfiles. Mediciones según encuestas confiabilidad, seguridad, servicio y garantías. Grupos objetivos 1, 2, 3

Fuente: Elaboración propia. 


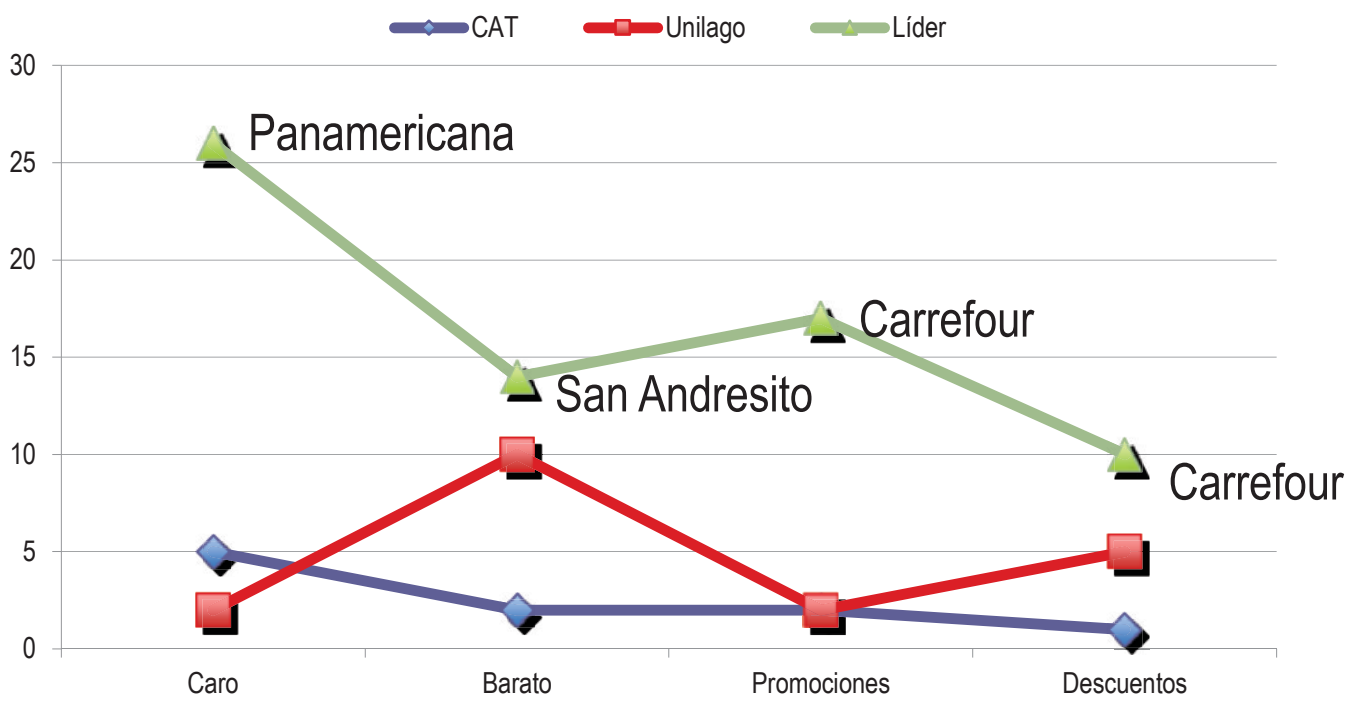

Figura 7. Comportamientos de las diferentes áreas en superficies de acuerdo con percepción en costos, promociones y descuentos Fuente: Elaboración propia.

\section{CONCLUSIONES}

Con respecto a los temas de percepción sobre los centros de alta tecnología tipo CAT, Unilago y San Andresito, se observó que es imaginaria, lo que significa tener un posicionamiento potencial. El nivel de conocimiento real de la marca CAT, frente a otros tipos de retail, es baja, por cuanto cuatro de cada 10 personas afirma saber cómo llegar; sin embargo, no hay orden en la compra, en el parqueo y en la vías de comunicación, lo cual hace confuso el acceso, las salidas y el tema de seguridad.

Los consumidores de alta tecnología, provenientes de estratos 2 y 3 del sector Sur de Bogotá, prefieren llegar a Unilago y el CAT en busca de precios y facilidades en los descuentos y promociones. Los consumidores de estratos 4 a 6 , es decir, grupos objetivos 3 y 4 , desean calidad en la entrega y la compra, garantía sobre precios y facilidad en el pago a crédito con tarjetas, aspectos que los lleva a ser clientes fieles de los centros de retail que permiten y promocionan dichas facilidades, como, por ejemplo, en Carrefour, Panamericana y K Tronix. En este sentido, prefieren Alkosto. Estos perfiles de consumo son usuarios que gustan de asesorarse de alguien de confianza, aunque paguen en efectivo.

El cliente objetivo 2, conformado por habitantes de estratos 3 y 4 del norte de Bogotá, los consumidores de este sector eligen garantía y atención, pero también precio y cercanía. Aunque optan por pagar en efectivo, existe una mayor frecuencia de compra con tarjeta de crédito, si se compara con el perfil anterior. Por el contrario, las personas del grupo objetivo , que son consumidores habituales del Centro de Alta Tecnología, procuran características importantes como precio, descuentos, promociones y accesorios. Ellos son generalmente usuarios que tienen mayor conocimiento del tema y les gusta indagar más. Las 
principales peculiaridades por las que eligen ir al CAT son la variedad, confiabilidad y experticia.

Definitivamente, en compras de nuevas tecnologías, para los estratos 2 y 3 el precio se vuelve un factor determinante a la hora del negocio, por encima de la marca de los productos. En cambio, en el retail, su disposición sí está directamente asociada con los métodos de financiación y no necesariamente con las garantías. Esto quiere decir que frente a la tienda de venta al detal, se percibe que el CAT ofrece productos variados y más baratos pero no ofrece mejor asesoría. Los clientes quieren asesoría imparcial.

En cuanto a las decisiones de compra en el CAT y Unilago, el consumidor se muestra satisfecho y manifiesta volver a comprar, lo que hace que tales centros de venta se vuelvan líderes en el mercado. Definitivamente, los productos más solicitados y de mayor rotación son los computadores y las marcas más reconocidas en HP y Sony. El precio se vuelve un factor determinante a la hora de la compra, por encima de la misma marca de los productos (aunque no se acepte abiertamente). Por el contrario, los individuos que compran en centros de ventas especializados y en las grandes superficies, buscan más la comodidad, la seguridad, las vías de comunicación, el compromiso y la garantía, además de las formas de pago con tarjetas de crédito, de cuentas de ahorro y con financiación.

Por lo explicado, no aparece clara la competitividad entre los centros de venta de productos de alta tecnología tipo CAT, Unilago y sanandresitos con los centros de venta de tecnología y gadget localizados en grandes superficies y centros comerciales. Esto, por cuanto las percepciones y los perfiles del segmento de consumo son diferentes para cada uno de los casos. Mientras en el CAT, San Andresito y Unilago importa el precio, la facilidad de descuentos y regateo, y los estratos y perfiles de clientes pertenecen a los estratos 2 y 3, del sur de la ciudad, en los centro de alta tecnología, de retail y centros comer- ciales, sus diferenciadores son la seguridad, las vías de comunicación, la facilidades de pago, créditos, financiación, comodidad y garantías extendidas, así como el historial de la compra, pues los clientes se pueden volver habituales debido a la facilidad de adquirir otro tipo de tecnologías.

En cuanto a los horarios del CAT, Unilago y San Andresito, regularme son de 9 am a 7 pm, mientras que los de los centros comerciales y de retail, por lo general, son de 9 am a 9 pm y los fines de semana de 9 am a 10 pm, con horarios extendidos en los casos que tienen mayor acogida.

\section{REFERENCIAS}

Arellano, R. (2002). Comportamiento del consumidor: Enfoque América Latina. Lima: McGraw-Hill.

Berman, B. (2007a). Retail management: A strategic approach. New Delhi: Pearson education.

Brennan, D. (2007b). Retail marketing forum 2007. Trends and innovations in retailing. St. Paul, Minnesota, USA: University of St. Thomas.

Brett King, D. \& M. Wertheimer. (2009). Max Wertheimer and Gestalt Theory. Third printing. New Jersey, USA: Transaction publishers.

Cáceres G., A. (2013). La Percepción del Color en la imagen. Bogotá DC: Facultad de Ciencias Económicas y Administrativas, ECCl.

CEPAL. (2009). Balance preliminar de las economías de América Latina y el Caribe, Revista de la Cepal, 100.

Clifton, R. (2009). Brands and branding. Second edition. Toronto, Canada: Profile Books.

Corporación CDT de GAS (2013). Un nuevo método para diseminar y aplicar la metrología, comunicación y trasmisión de datos, Revista semestral especializada en Metrología de fluidos Met \& Flu, 8. 
Franzen, G. \& S. Moriarty. (2009). The science and art of branding. Brand personality. USA: Library of Congress, cataloging in publication data, M.E Sharpe.

Gamboa P., I. F. (2010). Centro de estudios empresariales para la perdurabilidad. Publicación informal. Bogotá DC: Facultad de Administración, Universidad del Rosario.

Gil J., A. (2004). Psicología económica y del comportamiento del consumidor. Barcelona: UOC.

Global Powers of Retailing. (2011). Perspectives from deloitte, Leaving Home geographical analysis. [Global Economic Outlook]

Global Powers of Retailing. (2013). Retail Beyond, Deloitte, Retail perspectives from Deloitte. Global Powers of Retailing product sector analysis $\mathrm{G}_{18}$

Global Powers of Retailing. (2014). Retail beyong begins Products sector analysis. Global Powers of Retailing product sector analysis $\mathrm{G} 23$

Healey, M. (2008). ¿What is Branding? Essential design handbooks, New York, NY: Rotovsion, Sheridan House.

Honghua, T. (2013). Technology for education and learning (Advances in intelligent and soft computing). Qingdao, China: Springer.

Kardes, F.; Cronley, M. \& Cline, T. (2011). Consumer Behavior, Factor Influencing Market segmentation strategies. USA: Cengage Learning.

Magazine The Deloitte Touche Tomatsu "consumer review", reinventing the rol of the Higt Street Changing de $\mathrm{mlx}$ (pag11). [No está clara esta referencia]

Malhotra, N. (2010). Marketing research: An applied orientation. 6 ed. Bingley: Pearson Education UK.

Malhotra, N.; Birks, D. \& Wills, P. (2012). Marketing research: An applied approach. Washington, USA: Pearson Education.

Nokia Industry (2013), Connectivity Scorecard results highlights the continued need for investment in in- formation and communications technology (ICT) to stimulate a return to economic growth

Perspectivas de la Economía Mundial Informe World Economic Outlook (WEO) - Recovery Strengthens . Octubre de 2013 Fondo Monetario Internacional .

Pike, A. (2011). Brands and branding geographies. Northampton, Massachusetts: Edward Elgar.

Rajagopal, S.; Rajagopal, K. \& Lefkowitz, R. J. (2010). Teaching old receptors new tricks: biasing seventransmembrane receptors, Nat Rev Drug Discov, 9(5). doi: 10.1038/nrd3024, pp. 373-386.

Rodríguez, F. M. y M. Vargas P. (2006). Capacidades tecnológicas, innovación y competitividad de la industria de Bogotá y Cundinamarca Resultados de una encuesta de innovación. Bogotá DC: Cámara de Comercio de Bogotá, Observatorio Colombiano de Ciencia y Tecnología, Fondo Cultural Javeriano de Artes Gráficas.

Rudolph, T.(2012 Page 43) European Retail Research, Volume 26, Issue I, Número 1

Schroeder, C. (2010) Specialty, shop retailing, Everything you need to Know to run your own store. Third edition. Canadá: John Wiley and Sons.

Spiegel, A. (1991). Strategic Health Planning: Methods and Techniques Applied to Marketing. USA: Ablex Publishing Corporation.

Stephanie, L. (2013). Global Retail Report, Retailers are increasingly becoming global Latin American retailers in U.s trillion, A Report by UNI Global Union, October.

Stern, W. L.; El-Ansary, A.; Couglan, A. y Cruz [Completar] (1999). Canales de comercialización estructura funciones y relaciones. $5^{\text {a }}$ ed. México DF: Prentice Hall,

Wright, R. (2006). Chances and restrictions of measuring consumer behavior in the automotive. London, England: Thomson Learning. 